\title{
Genel Anestezi Altında Histeroskopi Sonrası İdiyopatik Fasiyal Sinir Paralizisi
}

\author{
Idiopathic Facial Nerve Paralysis after Hysteroscopy under General Anesthesia
}

Volkan Baytaș, Ahmet Onat Bermede, Șeyda Özalp, Könül Haciyeva, Asuman Uysalel

Ankara Üniversitesi Tıp Fakültesi, Anesteziyolojive Reanimasyon Ana Bilim Dall, Ankara, Türkiye
Geliș Tarihi :17.04.2016• Kabul Tarihi: 05.05.2016

\section{Iletișim}

Uz. Dr. Volkan Baytaș

E-posta: volkanbaytas@yahoo.com

Tel: 5957241

Ankara Üniversitesi Tıp Fakültesi, Anesteziyoloji ve Reanimasyon Ana Bilim Dalı, Ankara,Türkiye

\begin{abstract}
Periferik fasiyal paralizilerin \%50'sinden fazlası idiopatiktir (Bell paralizisi). İkinci sırada travmalar (yaklașık $\% 20)$, üçüncü sırada enfeksiyöz nedenler gelir.

Postoperatif fasiyal paralizi; genel anestezi uygulamalarında maske ile havalandırma sırasında veya hasta pozisyonuna bağlı altında sinire kompresyon veya sinirin gerilmesine bağlı olușabilen nadir bir komplikasyondur. İntraoperatif hipotansiyon, hipovolemi, hipoksi, hipotermi, elektrolit imbalansı diğer risk faktörleridir.

Endometriyal polip tanısıyla 38 yașında, American Society of Anesthesiology Classification. (ASA I) hastaya histeroskopi planlanmıștır. Larengeal maske ile genel anestezi uygulandı. Derlenme sonrasında hasta yüzünde uyușma șikayeti tariflemiștir. Fizik muayenede sağ kașını kaldıramadığı ve sağ nazolabial oluğun silindiği, fasial sinirin diğer dalları ve diğer kranial sinirlerin normal olduğu saptandı. Nöroloji konsultasyonunu takiben distal fasiyal sinir paralizisi tanısı kondu. Medikal tedavi sonrasında hastanın fasiyal paralizi tablosu üç hafta sonra tamamen düzelmiștir.

Bu vakada zor maske ventilasyonu yoktu ve hasta supin pozisyondaydı. Ayrıca operasyon süresince fasiyal paraliziye neden olabilecek bașka bir nedende saptanmadı. Hasta detaylı sorgulandığında operasyonun bir gün öncesinde prodromal kulak ağrısından yakındı. Biz fasiyal paralizinin operasyonla koinsidental olarak ortaya çıktığı, genel anestezi ve cerrahi stress faktörlerinin zaten gelișme sürecinde olan bu fasiyal paralizinin șiddetini arttırdığını düșünmekteyiz.

Anahtar Sözcükler: Genel Anestezi, Fasiyal Sinir, Paralizi

More than $50 \%$ of peripheral facial paralysis are idiopathic (Bell's palsy). Second frequent reason thought to be trauma (aproximately 20\%) and the infection as the third.

Postoperative facial paralysis is a rare condition that can appear probably due to compression to nerve upon mechanical stress or distention of nerve during mask ventilation via mask or due to patient positioning. Intraoperative hypotension, hypovolemia, hypoxia, electrolyte imbalance are other risk factors.

A 38-year-old American Society of Anesthesiology Classification. (ASA I) woman was scheduled for hysteroscopy due to endometrial polyp. Patient was operated with general anesthesia via larengeal mask. After recovery patient complained about facial paresthaesia. It was defined that patient could not lift the right eyebrow and right nasolabial fold was erased and rest of the branches of facial nerve and other cranial nerves were normal. Distal facial nerve paralysis was diagnosed after neurological consultation. Patient fully recovered in three weeks after medical treatment.

In this case there was no difficult mask ventilation and patient was in supine position. Also there was no any other reason give rise to facial paralysis during surgery. When patient questioned in detailed she complained prodromal earache one day before the operation. We believe that facial paralysis coincided with the operation, factors of general anesthesia and surgical stress increased the severity of this pathology that had already been in development process.

Key Words: General Anesthesia, Fascial Nerve, Paraliysis
\end{abstract}

Fasiyal sinir; yüz kaslarını innerve eden motor, tükrük bezlerine giden parasempatik, dil 2/3 ön kısminin tad duyusunu alan afferent, diş kulak yolu ve kulak kepçesinin duyusunu alan somatik afferent lifleri içeren bir sinirdir (1) (Şekil-1). Periferik fasiyal paralizilerin $\% 50$ 'sinden fazlası idiopatiktir (Bell paralizisi). İkinci sirada travmalar (yaklaşık \%20), üçüncü sırada enfeksiyöz nedenler gelir. Diğer sebepler ise neoplastik, konjenital, metaboliktir (2). Bell paralizisi akut başlangıçlı olup yüz kaslarını genellikle tek taraflı olarak tutar. Yüz kaslarında paralizi veya güçsüzlükle ortaya çıkar (3). Etkilenmiş taraf kulak çevresi veya arkasında olan bazen oksipital, servikal bölgeye yayılan ağr1 da görülebilir (4). Bell paralizisi gebelerde ve diabetes mellitus, üst solunum yolu hastalıkları, influenza enfeksiyonu olan hastalarda daha 
sık görülür (5). Bu olguda postoperatif dönemde çok nadir gözlenen fasiyal paralizinin etiyolojisini araştırırken, literatürdeki diğer vakalarla tartışmayı amaçladık (Şekil 1).

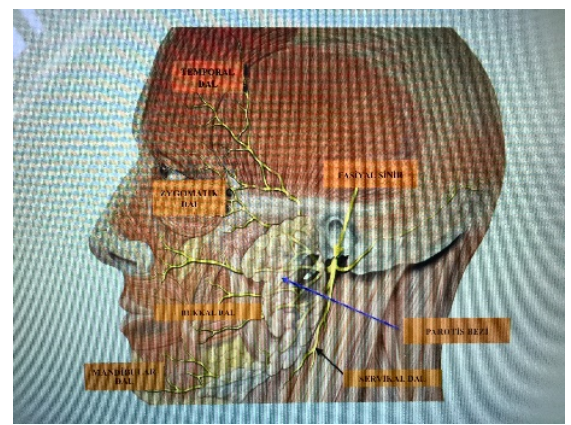

Şekil 1: Fasiyal Sinir Anatomisi (10)

\section{Olgu}

Endometriyal polip tanısıyla 38 yaşında $\mathrm{k}$ American Society of Anesthesiology Classification. (ASA I), kadin hastaya histeroskopi planlandi. Preoperatif değerlendirmesinde ek sistemik hastalığ1 olmadığ tetkiklerinde patoloji saptanmayan hastanın yapilan fizik muayenesi normal, ağız açıklığı $4 \mathrm{~cm}$ den fazla, Mallampati skoru I olarak saptandi. Yaklaşık 1 saat süreceği öngörülen operasyon için larengeal maske ile genel anestezi planlandi. Hasta bilgilendirilerek onamı alındı. Operasyon odasinda supin pozisyona alinan hastanın rutin monitorizasyonunu takiben anestezi indüksiyonuna başlandi. İndüksiyonda intravenöz $0.5 \mathrm{mg} / \mathrm{kg}$ lidokain $\mathrm{HCl}$ (Aritmal \%2 ampül, Osel İlaç A.Ş), $4 \mathrm{mg} / \mathrm{kg}$ propofol ( Propofol Lipuro \%1, Braun Medical), $0.1 \mathrm{mcg} / \mathrm{kg}$ remifentanil (Ultiva, Glakso Smith Kline) verildi ve sonrasında hastaya yaklaşık 2-3 dk maske ventilasyonu uygulandi. Yeterli anestezi derinliğine ulaşılmasını takiben 3 numara laringeal maske (Fas Trach) yerleştirildi. Maske ventilasyonu esnasında zorluk yaşanmamış olup gereğinden fazla dijital bası uygulanması gerekmemiştir. Laringeal maske tek seferde zorluk yaşanmadan yerleştirilmiştir. Laringeal maske yerleştirilmesini takiben hasta histeroskopik girişim için litotomi pozisyonuna alındı. Anestezi idamesinde sevofluran ( Sevorane, Abbot) (1,3 MAC) kullanıldı.
Bası ve gelişebilecek muhtemel sinir hasarlarına karşı hasta uygun pozisyonda sabitlendi, basiya maruz kalabilecek vücut bölgeleri, baş ve yüz bölgesi jel yastıklarla desteklendi. Isıtıc1lar yardımiyla operasyon sürecinde hastanın normotermik kalması sağlandi. Hastaya hesaplanan miktarda sıvı replasmanı yapılmış olup operasyon esnasinda ek sivı ihtiyacı olmamıştır. Yaklaşık 1 saat süren operasyon esnasında hemodinamik açıdan, solunum fonksiyonları açısından herhangi bir sorun gözlenmemiş olup hasta sorunsuz şekilde uyandirıldi. Derlenme aşamaşında ise yaklaşık 4 $\mathrm{dk}$ maske ventilasyonu zorluk yaşanmadan sorunsuz olarak uygulandi. Hasta derlenme ünitesinde $20 \mathrm{dk}$ takibin ardından servis odasına alındı. Operasyon bittikten yaklaşık 2 saat sonra serviste takibi esnasinda hasta yüzünde uyuşma şikayeti tariflemiştir. Hastanın yapilan fizik muayenesinde sağ kaşını kaldıramadığı ve sağ nazolabial oluğunun silindiği saptand. Diğer fasiyal sinir dalları ve kranial sinirler normal olarak değerlendirildi. Fasiyal paralizi ön tanısı ile nöroloji konsültasyonu istendi. Nöroloji tarafindan değerlendirilen hastanın nörolojik muayenesinde ve kraniyal bilgisayarlı tomografisinde patoloji saptanmadı ve periferik fasiyal sinir paralizisi tanisiyla 1 hafta metilprednizolon prednol $16 \mathrm{mg}$, Mustafa Nevzat İlaç A.Ş) 4x16 mg, asiklovir 20 $\mathrm{mg} / \mathrm{kg} /$ gün olarak medikal tedavi başlanması önerildi. Uygulanan bu medikal tedavi sonucu paralizi yaklaşık 3 hafta sonra tam düzelmiştir.

\section{Tartıșma}

İdiyopatik fasiyal paralizi (Bell paralizisi) sık görülen bir nöropatidir. Hastaların çoğu tamamen iyileşir (6). Sinir hasarı için; iskemi, mekanik kompresyon, uygun olmayan pozisyonlara bağli sinir gerilmesi, iğne hasarı ve nörotoksik materyal enjeksiyonu gibi çok sayıda mekanizma ileri sürülmüştür. Diabetes Mellitus varllğ 1 bu sinir hasarı insidansını arttırmaktadır (7).

Postoperatif fasiyal paralizi; genel anestezi altında mekanik strese bağlı sinir kompresyonu veya sinirin gerilmesine bağlı oluşabilen nadir bir komplikasyondur. Mandibulaya direkt bas1 veya maske ile havalandirma sirasinda maskenin basisı ile fasiyal sinir travması oluşabilir (6). Bizim vakamızda operasyon esnasinda hastanin maske ventilasyonunda zorluk yaşanmamış ve mandibulaya sinir hasar1na yol açabilecek bir bası uygulanmamıştır.Operasyon litotomi pozisyonunda ve sinir basıları önlenecek biçimde hasta desteklenerek gerçekleştirildi. Dolayısıyla fasiyal paralizinin maskenin mekanik bas1sına veya hasta pozisyonuna bağlı olduğunu düşünmedik.

Fasiyal paraliziye eşlik eden semptom ve bulgular da ayırıcı tanı için önemlidir. Sıklıkla bazı hastalar paralizi öncesi günlerde aynı taraf kulak ve çevresinde ağr1 tanımlar. Ayrıca hastalarda yüzde hipoestezi, hiperakuzi, göz yaşında azalma ve tad alma değişikliği de görülebilir (7). Bizim vakamızda bu bulgulardan sadece operasyondan bir gün önce başlayan kulak ağrısı saptandi. Bu durum hastalığın preoperatif dönemde gelişim sürecinde olduğunu düşündürdü ve hastalığın operasyon esnasında gelişmiş olabileceği ihtimalinden uzaklaştırdı.

Intraoperatif hipotansiyon, hipovolemi, hipoksi, hipotermi, elektrolit imbalansı diğer risk faktörleridir (7). Bu olguda intraoperatif hemodinami açsından herhangi bir sorun yaşanmamiş olup, hipotermi, hipoksi ve hipovolemi de gözlenmemiştir.Dolayısıyla neden olabilecek bu risk faktörleri de fasiyal paralizinin etyolojisinde düşünülmemiştir.

Lonjaret ve ark.lar1 (8) bildirdikleri bir vakada kronik pankreatit sebebiyle opere olan 66 yaşındaki bir hastada postoperatif fasiyal paralizi saptamışlardır. Bu vakada da bizim vakamızda olduğu gibi ameliyattan bir gün önce kulak ağrisı mevcut olup, operasyon sonrası bakım ünitesinde takip edilirken periferik fasiyal paralizi saptamışlardir. Kranial tomografisi normal gelen hastaya prednizolon tedavisi uygulanmıştır. Bu hastada paralizi tablosu gelişiminde maske ventilasyonu veya diğer sayılan nedenler düşünülmemiş ve prodromal semptom göz 
Önüne alındiğında bu tablonun hasta genel anestezi almasa da gelişebileceği, genel anestezinin paralizinin şiddetini arttırmış olabileceği kanısına varmışlardır. Bizim vakamızda da prodromal kulak ağrısının olması ve fasiyal paraliziye neden olabilecek diğer etkenlerin olmaması nedeniyle aynı kanıdayı.

Baidya ve ark.ları (7) laparoskopik kolesistektomi ve histerektomi geçiren 62 yaşındaki hastalarında indüksiyon esnasında yaklaşık 3 dakika maske ventilasyonu uygulamışlar ve hastalarında operasyon sonrası dönemde fasiyal paralizi saptamışlardır. Gelişen paralizi tablosunun sebep olabilecek diğer nedenleri dişladıktan sonra maske ventilasyonuna, maskenin çeneye kuvvetli basısına bağlı olabileceğini düşünmüşler, bu durumun maske ventilasyonu çok kısa süre olsa da gelişebileceğini ve sıkı maske uygulamasından mümkünse kaçınılması gerektiğini vurgulamışlardır. Paralizi tablosunun yaklaşık 6 hafta sonra düzeldiğini bildirmişlerdir.Bizim hastamızda da maske ventilasyonu süresi kısaydı.Çeneye kuvvetli basıya neden ola-

\section{KAYNAKLAR}

1. Bayındır T, Tan M, Selimoğlu E. Bell Paralizisinde Tanı ve Tedavi Yöntemleri. Kuak Burun Boğaz ve Baş Boyun Cerrahisi Dergisi 2011; 10: 18-30

2. Cansız H, Pamukçu M, Edizer T. Fasiyal Paraliziler. Klinik gelişim 2005; 18:96-104

3. Gagyor I, Madhok VB, Daly F et al. Antiviral treatment for Bell's palsy (idiopathic facial paralysis). Cochrane Database Syst Rev. 2015; 9:11

4. Burges LP, Yim DV, Lepore ML. Bell's palsy: the steroid controversy revisited. Laryngoscope.2009; 94: 1472-1476 cak maske uygulaması söz konusu olmadığından bu etyolojiyi dışladık.

Glabour (9) maske ventilasyonu ile genel anestezi sağlanan, spontan solunumu olan hastada 75 dakikalık operasyonun ardindan bilateral fasiyal paralizi bildirmiştir. Bu vakada mandibula angulus bölgesine bilateral dijital bask1 uygulandığ ve fasiyal paralizi tablosunun 3 haftada tamamen düzeldiği bildirilmiştir. Bizim olgumuzda, bu vakada olduğu gibi uzun bir maske ventilasyonu olmadiğından ve maskeyle ventilasyon esnasinda herhangi bir zorlanma, dijital baskı söz konusu olmadığından bu etiyoloji dışlanmıştır.

Olguların \%80-85 inde, haftalar içinde, en fazla bir ya da ikinci ayda düzelme görülür. (7) Bizim vakamızdaki fasiyal paralizi tablosu da uygulanan medikal tedavi sonucu yaklaşık 3 hafta sonra düzelmiştir.

\section{Sonuç}

Genel anestezi sonrası fasiyal paralizi gelişimi anestezistlerin çok ender karşılaştığ1 bir durumdur. Operasyon esnasinda gelişen fasiyal paralizinin ne-

5. Prescott CA. İdiopathic facial nerve palsy (the effect of treatment with steroids). Journal of Laryngology and Otology 1988; 102: 403-407

6. Ananthanarayan C, Rolbin SH, Hew E. Facial nerve paralysis following mask anaesthesia.Canadian Journal of Anaesthesia 1988; 35: 102-103

7. Baidya DK, Bhoi D, Sinha R et al. Partial facial nerve paralysis after laparoscopic surgery under general anaesthesia.Indian Journal of Anaesthesia. 2011; 55: 416-418 denleri; uygun olmayan hasta pozisyonlar1, hipotansiyon, hipovolemi, hipoksi gibi nedenler olmakla birlikte literatüre bakıldığı zaman az rastlanan bu durumun nedeni genellikle maske ventilasyonu sonucu gelişen basıya bağlanmıştır. Zor hava yolu, özellikle de zor maske ventilasyonu olan hastalara daha sik rastlanmaktadir. Zor maske ventilasyonu sonucu basiya bağlı fasiyal paralizinin gelişebilecek bir komplikasyon olduğu unutulmamalıdır. Bizim vakamızda olduğu gibi operasyon esnasında paraliziye yol açan herhangi bir etken olmamasina karşın bu tablo gelişebilir. Bu grup hastada Bell paralizisine ait prodromal belirtiler geriye dönük dikkatlice sorgulanmalıdır. Sonuç olarak bu hastada preoperatif dönemde var olan aynı tarafta olan kulak ağrısı göz önüne alındığında, bu operasyon gerçekleşmese bile paralizinin gelişebileceği, paralizi gelişim sürecinin operasyon dönemine denk geldiği, genel anestezi ve cerrahi stres faktörünün zaten gelişme sürecinde olan bu patolojinin şiddetini arttırdığını düşünmekteyiz.

8. Lonjaret L, Vuillaume C, Fourcade O et al Idiopathic facial paralysis following general anesthesia.Journal of Anaesthesiology Clinical Pharmacology. 2012; 28: 536-537

9. Glabaur DT. Facial nerve paralysis after general anaesthesia. Anesthesiology. 1986; 65: 516-517

10. Lakraj AA, Moqhimi N, Jabbari B. Sialorrhea: anatomy, pathophysiology and treatmentwith emphasis on the role of botilinum toxins. Toxins(Basel) 2013; 21: 1010-1031 
